\title{
Hydro-urban London
}

\author{
Tse-Hui Teh
}

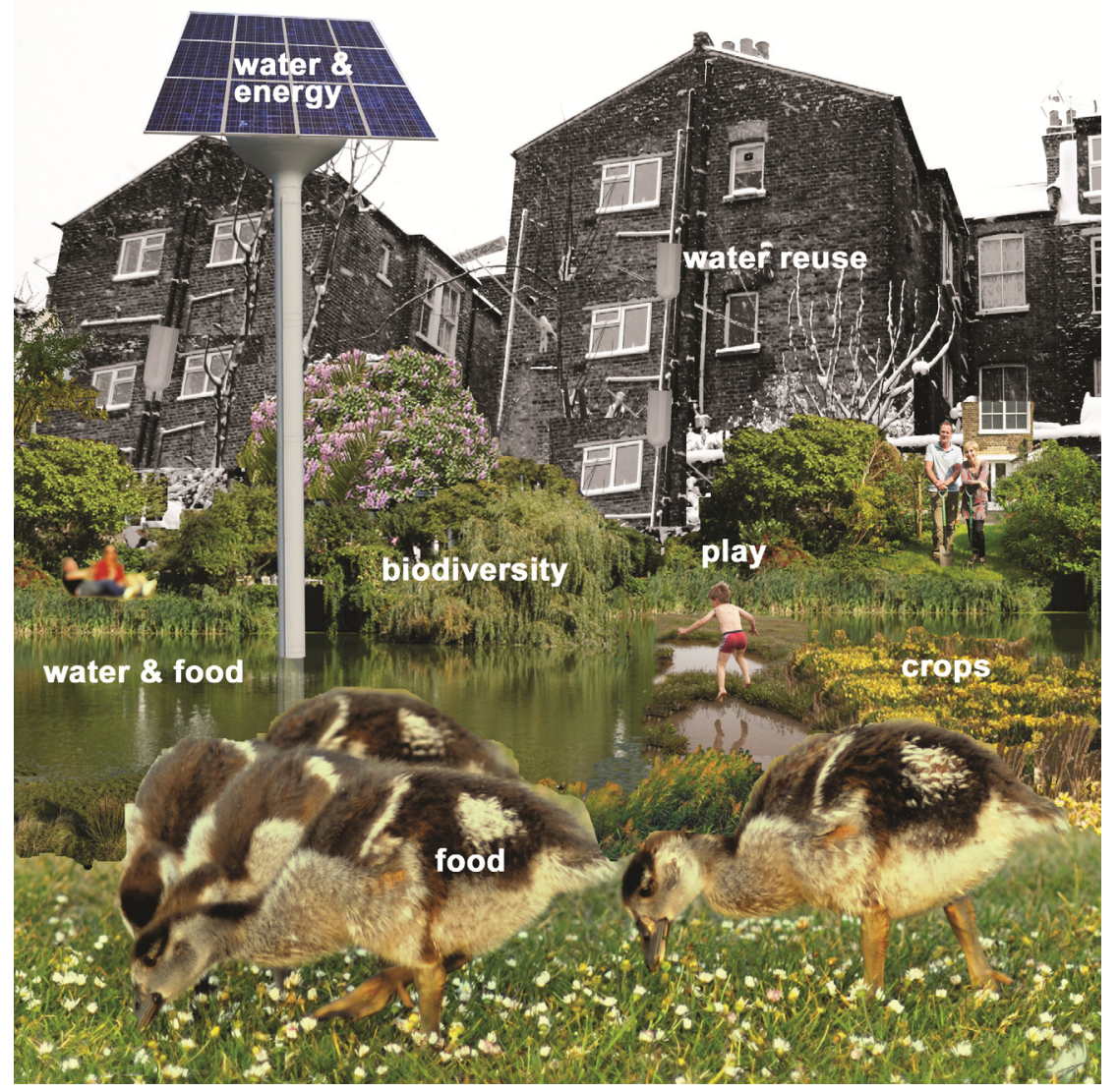

Figure 1: Photomontage of new infrastructure spaces for water reuse, energy production, food production, biodiversity and recreation.

How to cite this book chapter:

Teh, T. 2013. Hydro-urban London. In: Bell, S and Paskins, J. (eds.) Imagining the Future City: London 2062. Pp. 95-96. London: Ubiquity Press. DOI: http://dx.doi.org/10.5334/bag.m 


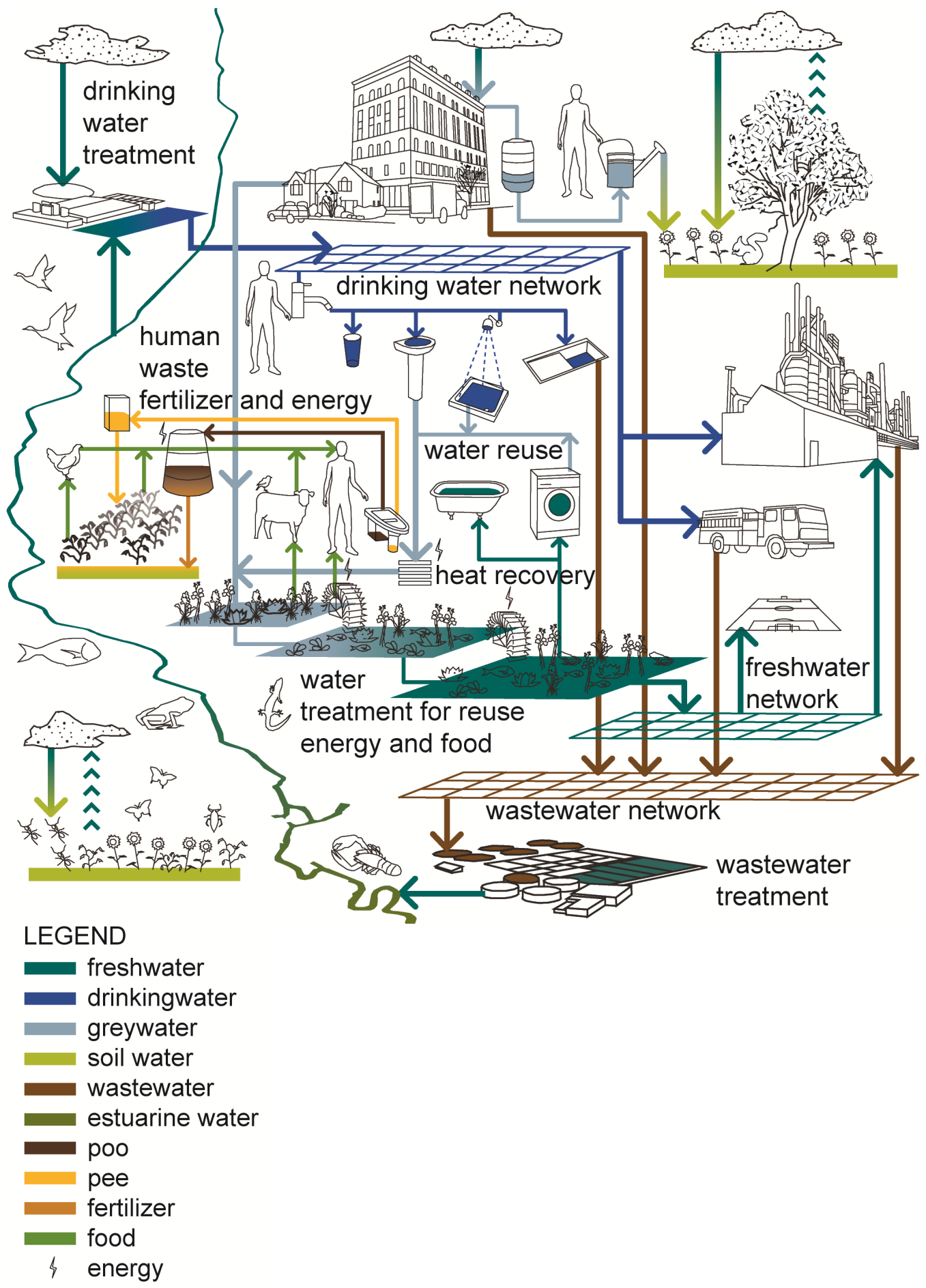

Figure 2: Diagram of water, food and fertilizer flows for the new infrastructure spaces of water reuse, energy production, food production, biodiversity and recreation. 